

ISSN 1412-3746

FAKULTAS KESEHATAN UNIVERSITAS DIAN NUSWANTORO

Persepsi Mahasiswa Keperawatan Tentang Eskalasi Tenaga Perawat

Rendi Ariyanto Sinanto', Vivi Retno Intening ${ }^{2}$

Risiko kesehatan $\mathrm{Pb}$ dan $\mathrm{Hg}$ pada sayuran di desa Kopeng Kabupaten Semarang

Indira Casheila Anindityo ${ }^{1}$, Nur Endah Wahyuningsih ${ }^{2}$, Yusniar Hanani Darundiati ${ }^{3}$

Analisis Pelaksanaan Program Indonesia Sehat Dengan Pendekatan Keluarga (Pispk) Dalam Capaian Indeks Keluarga

Sehat Di Kabupaten Brebes Tahun 2020 Studi Pada Puskesmas Kluwut Kabupaten Brebes

Rizky Aprilianti Lestari ${ }^{1}$ dr. Antono Suryoputro ${ }^{1}$ Dr. dr. Apoina Kartini. M. Kes ${ }^{1}$

Disiplin Keselamatan dan Kesehatan Kerja melalui pemakaian alat pelindung diri di laboratorium kimia PT Sucofindo

Jakarta

Susan Endah Kartikasari ${ }^{1}$, Tatan Sukwika ${ }^{2}$

Perbedaan Pengetahuan Anemia dan Tablet Tambah Darah (TTD) Sebelum dan Sesudah Pendidikan Kesehatan Melalui

Media Video dan Aplikasi Quizlet

Devita Sari ${ }^{1}$, Gisely Vionalita ${ }^{2}$

Tingkat Pengetahuan Dan Perilaku Mahasiswi Mengenai Legalitas Dan Keamanan Kosmetik

Hani Sri Fitriani, Rizki Siti Nurfitria

Evaluasi Manajemen Dokumen Rekam Medis Di Filing Aktif Rumah Sakit Swasta Kabupaten Semarang

Bobby Anggara Laksana Putra ${ }^{1}$, Retno Astuti Setjaningsih ${ }^{2}$

Tingkat Pengetahuan Gizi Seimbang dan Profil Kesehatan Sopir Bus Antar Kota

Vilda Ana Veria Setyawati ${ }^{1}$, Bayu Yoni Setyo Nugroho ${ }^{1}$

Pengaruh Pengetahuan Dan Motivasi Kerja Terhadap Penerapan Early Warning Score System Di Rsup H Adam Malik Ita Riahna Pinem ${ }^{1}$, Zulfendri', Siti Saidah Nasution ${ }^{3}$

Analisis Penelusuran Masker Sebagai Protokol Kesehatan Saat Pandemi Covid-19 Di Indonesia: Studi Google Trends Ully Febra Kusuma ${ }^{1}$, Nurunnisa Arsyad ${ }^{2}$, Melissa Shalimar Lavinia ${ }^{3}$, Selvia Rahayu ${ }^{4}$, M. Khairul Kahfi , Rizma Adllia Syakurah ${ }^{6}$ Perilaku Hidup Bersih Dan Sehat (Phbs) Dengan Kejadian Sakit Pada Siswa Sekolah Dasar Di Kabupaten Banyumas Windri Lesmana Rubai ${ }^{1}$, Pramesthi Widya Hapsari', Katri Andirini Surijati ${ }^{3}$

Identifikasi Risiko Ganguan Muskuloskletal Pada Pekerja Percetakan Dengan Metode Nordic Body Map

Octavianus Hutapea ${ }^{1}$, Moch.Sahri', Rustam Basuki ${ }^{3}$

Literatur review: Implementasi Bauran Pemasaran 7P Terhadap Tingkat Kepuasan Pasien Di Rumah Sakit

Desi Natalia Marpaung ${ }^{1}$ Ernawaty $^{2}$ Diansanto Prayoga ${ }^{3}$ Syifa'ul Lailiyah $^{4}$

Kelengkapan Informasi Medis Untuk Mendukung Kodefikasi Penyakit Jantung Guna Mewujudkan Kualitas Data Informasi Medis Di Rumah Sakit Islam Sultan Agung Semarang

Dyah Ernawati ${ }^{1}$, Ratna Rifatul Ulya ${ }^{2}$, Arif Kurniadi ${ }^{3}$

Kajian Faktor Kendala Dokter Tidak Menggunakan Aplikasi Wifi Tb Di Kota Semarang

Arif Kurniadi', Evina Widianawati2, Dyah Ernawati ${ }^{3}$

Analisis Pelaksanaan Program Penanggulangan Tuberkulosis Paru Di Puskesmas Purwoyoso Kota Semarang

Nahari Ratu Cempaka Wilis ${ }^{1}$ Hardi Warsono ${ }^{2}$ M. Sakundarno Adi ${ }^{3}$

Hubungan Penggunaan Alat Pelindung Diri (Apd) Dengan Kadar Sgot Dan Sgpt Dalam Darah Pada Petani Padi

Iga Maliga, Rafi'ah

Faktor Risiko Kejadian Stunting Pada Balita di Wilayah Kerja Puskesmas Pandan Kabupaten Sintang

${ }^{1}$ Agustini Elisabet, ${ }^{2}$ Elvi Juliansyah

Peran Suami Dan Petugas Kesehatan Dengan Deteksi Dini Kanker Serviks

Christina Leasa, ${ }^{1}$ Mariene Wiwin Dolang

Analisis Penerapan Protokol Kesehatan terhadap Tingkat Kepatuhan Pada Pekerja informal Selama Pandemi Covid-19

MG Catur Yuantari ${ }^{1}$, Enny Rachmani ${ }^{2}$, Eti Rimawati ${ }^{1}$, Sri Handayani ${ }^{1}$, Edi Jaya Kusuma ${ }^{2}$

Peran Pengawas Minum Obat Dan Pendampingan Berobat Ulang Dengan Keberhasilan Pengobatan Tb Paru

Taswin $^{\left.1^{*}\right)}$, (zan $^{1)}$, Wahyuddin $^{1)}$, Dahmar ${ }^{1)}$

Faktor Determinan Sosial Dan Gambaran Kejadian Post Traumatic Syndrome Disorder (Ptsd) Pasca Banjir Di Dki Jakarta

Dan Bekasi Tahun 2020

Thresya Febrianti ${ }^{1}$, Nurfadhillah ${ }^{2}$, Mitha Nurhjanah ${ }^{3}$, Tiara Kautsa Aliefya ${ }^{4}$

Perbedaan Pola Makan Pada Balita Stunting Dan Tidak Stunting Di Kecamatan Teon Nila Serua (Tns) Kabupaten Maluku Tengah

Trixie Leunupun ${ }^{1}$, Ani Margawati' ${ }^{2}$ Annastasia Ediati ${ }^{3}$

Gambaran Pengelolaan Rekam Medis Rawat Inap Di Rsud Syekh Yusuf Kab. Gowa Tahun 2019

Zilfadhilah Arranury*, Surahmawati, Muhammad Rusmin, Tri Addya Karini, Dian Rezki Wijaya, Ranti Ekasari, Jihan Sulfitri

Analisis Risiko Kesehatan dalam Pemanfaatan Kemball Limbah Sludge Industri Makanan PT. X

Sri Slamet Mulyati ${ }^{1}$, Fajar Sihite ${ }^{2}$ 


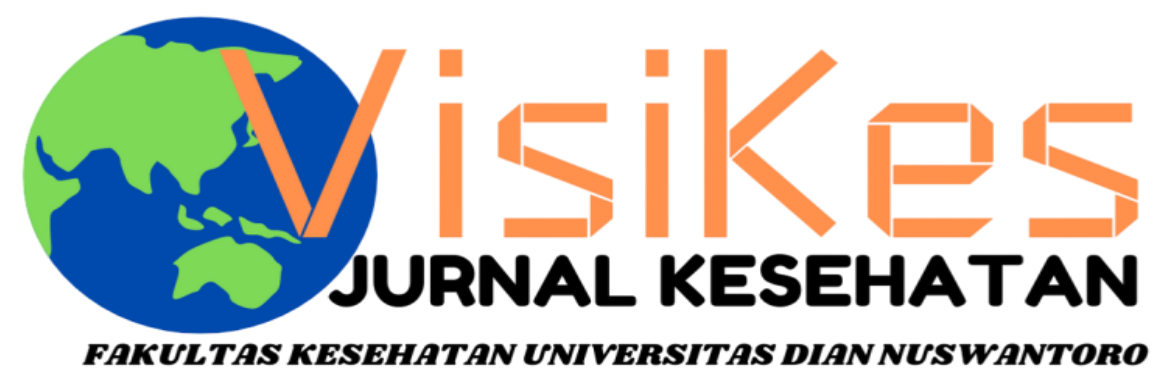

Volume 20, Nomor 1, April 2021

\section{Ketua Redaksi}

Dr. Drs. Slamet Isworo, M.Kes

\section{Penyunting}

Enny Rachmani, SKM, M.Kom, Ph.D

Fitria Wulandari, SKM, M.Kes

\section{Sekretariat}

Lice Sabata, SKM

Desain dan Layout

Puput Nur Fajri, SKM

\section{Alamat Redaksi}

Fakultas Kesehatan Universitas Dian Nuswantoro Jl. Nakula I No. 5-11 Semarang Telp/fax. (024) 3549948

email : visikes@fkes.dinus.ac.id

website $\quad$ : http://publikasi.dinus.ac.id/index.php/visikes/index

VisiKes diterbitkan mulai Maret 2002

Oleh Fakultas Kesehatan Universitas Dian Nuswantoro 


\title{
Evaluasi Manajemen Dokumen Rekam Medis Di Filing Aktif Rumah Sakit Swasta Kabupaten Semarang
}

\author{
Bobby Anggara Laksana Putra ${ }^{1}$, Retno Astuti Setjaningsih ${ }^{2}$ \\ 1,2 Prodi DIII Rekam Medis dan Informasi Kesehatan Fakultas Kesehatan Udinus \\ email: bobbyanggara360@gmail.com; retno.astuti@dsn.dinus.ac.id
}

\section{Kontribusi Penulis:}

Penelitian ini adalah hasil kontribusi 2 (dua) orang penulis. Penulis RAS merancang desain penelitian dan melakukan analisis data. Selanjutnya, RAS menarik simpulan, memberikan berbagai solusi pemecahan masalah, serta melakukan editing hasil akhir artikel ilmiah. Sedangkan penulis BALP mengumpulkan literatur dan data, mengolah dan menyajikan data, serta mengunggah pada jurnal. Semua penulis menyepakati naskah akhir untuk dipublikasikan melalui Jurnal Visikes.

\begin{abstract}
Missfile can inhibit medical services provided to patients without information about history. From the initial survey, it found 90 missile incidents (4.7\%) from 2000 medical record documents, the second survey found 578 incidents from 7000 medical record documents with $9.0 \%$ missfile. This study aims to identify the medical records management in the outpatient filing section of The Private Hospital, Semarang Regency in 2019. This research is a mix methode study. Data collection by observation and interview methods with a cross-sectional approach. The research subjects were 3 filing officers. The research objects to the management of medical record documents in the outpatient filing section. The research instrument used in this research were interview and observation guidelines. The number of polyclinics at The Private Hospital in Semarang Regency is 20 polyclinics. There should be a submission terminal so staff will not be tired. The hospital management facilities were adequate but have not been properly utilized by the officers, the officers should use these facilities to facilitate document tracking. The Hospital should make a policy regarding the management of medical record documents and use colour codes on the documents so that the staff can understand and carry out their duties properly.
\end{abstract}

Keywords: medical record management, storage systems, management standards

\section{PENDAHULUAN}

Rumah sakit sebagai salah satu fasilitas pelayanan kesehatan harus memberikan pelayanan kesehatan dengan berorientasi untuk menjamin keselamatan pengobatan seorang pasien. Pelayanan kesehatan yang bermutu ini diantaranya dengan menyelenggarakan rekam medis yang lengkap, cepat, tepat, dan akurat. ${ }^{(1)}$

Peraturan Menteri Kesehatan Republik Indonesia Nomor 269/ Menkes/ PER/ III/ 2008 yang mendefinisikan rekam medis menyatakan sebagai rekaman keterangan tentang data, anamnesis, pemeriksaan fisik, hasil pemeriksaan penunjan, pelayanan dan tindakan, pengobatan, serta terapi lain untuk pasien, baik di semua unit pelayanan kesehatan. Pasien memiliki hak atas data, tetapi fasilitas pelayanan kesehatan yang merawat pasien harus mengelola fisik dokumennya. Dengan demikian, fasilitas pelayanan kesehatan wajib mengelola, menjaga dan menyimpan rekam medis tersebut dengan benar dan aman. Selain itu, fasilitas pelayanan kesehatan juga wajib 
menjaga kerahasiaan informasi rekam medis. (2)

Bahkan Badan Organisasi Akreditasi Rumah Sakit di beberapa negara maju menyatakan bahwa rekam medis berperan penting dalam mengukur mutu pelayanan medis yang diberikan oleh rumah sakit beserta staf medisnya. ${ }^{(3)}$ Jadi, manajemen rekam medis harus tertib administrasi, diantaranya kewajiban adanya fungsi filing sebagai subunit yang mengelola rekam medis di suatu rumah sakit.

Salah satu filing rumah sakit swasta di Kabupaten masih menyelenggarakan rekam medis secara paper based. Pada awalnya, rumah sakit, filing menerapkan pengelolaan dokumen rekam medis aktif secara desentralisasi. Yakni, penyimpanan dokumen rekam medis rawat jalan dan gawat darurat seorang pasien dalam satu folder di filing rawat jalan. Sedangkan dokumen rekam medis rawat inap pasien tersebut disimpan dalam folder terpisah di filing rawat inap. Nomor rekam medis yang diberikan kepada pasien sebagai identitas pasien selain nama pasien sudah sama antara folder rawat jalan dengan folder rawat inap. Tujuan pemberian nomor rekam medis tersebut adalah guna mempercepat identifikasi data atau dokumen rekam medis seorang pasien, khususnya jika dating berobat lagi.

Selanjutnya, penyimpanan dokumen rekam medis pernah diubah menjadi system sentralisasi yang menggabungkan semua dokumen rekam medis seorang pasien, baik rawat jalan, gawat darurat, maupun rawat inap, ke dalam satu folder di satu rak file/ruang penyimpanan. Tentunya, sistem penyimpanan ini lebih ideal karena menjamin kesinambungan informasi medis seorang pasien. Dengan demikian, harapannya bisa menjamin keselamatan pengobatan pada diri seorang pasien yang harus menjadi prioritas utama suatu fasilitas pelayanan kesehatan.

Kenyataannya, hasil survei awal pada tahun 2019 ternyata filing rumah sakit ini kembali menerapkan sistem penyimpaanan desentralisasi. Perubahan sistem penyimpanan ini bertujuan agar rumah sakit bisa mempercepat pelayanan kepada pasien sejalan dengan kecepatan pelacakan dokumen rekam medis seorang pasien yang datang berobat kembali ke rumah sakit.

Manajemen rekam medis rumah sakit dengan sistem penyimpanan desentralisasi seperti ini harus mengelola dua jenis filing. Pertama, filing rawat jalan yang barada dekat dengan tempat pendaftaran pasien rawat jalan. Terdapat dua filing rawat jalan di rumah sakit ini, yakni berada di lantai satu dan tiga. Juga mengelola filing rawat inap yang berada di lantai lima.

Tujuan pemisahan filing untuk mempercepat pelayanan dokumen rekam medis pasien daripada penerapan penyimpanan sentralisasi ini belum sepenuhnya tercapai. Pada saat survei awal ternyata masih ditemukan kejadian salah letak dokumen rekam medis (missfile). Akibatnya, pelayanan kesehatan pasien di 
unit rawat jalan terkendala, diantaranya waktu tunggu pasien menjadi lebih lama daripada standar pelayanan minimal (SPM).

Berdasarkan hasil survei awal pada bulan November tahun 2018, ditemukan adanya 90 (4,5\%) dokumen dari 2000 dokumen rekam medis yang ada mengalami kejadian missfile. Peneliti melakukan observasi terhadap 10 kotak dari 590 seksi rak penyimpanan yang ada di ruang filing. 10 kotak tersebut mencakup 2000 dokumen rekam medis.

Berikutnya, berdasarkan sampel survei kedua sebesar 100 nomor rekam medis secara acak, didapatkan bahwa 9 (9\%) dokumen rekam medis salah letak (missfile). Juga menurut hasil survei ketiga pada bulan Juni tahun 2019, didapatkan adanya 578 (8.26\%) kejadian missfile dokumen rekam medis. Dilakukan observasi terhadap 30 kotak dari 580 kotak di ruang penyimpanan. 30 kotak tersebut menampung 7000 dokumen rekam medis. Hal ini menyebabkan waktu pelacakan dokumen rekam medis semakin lama.

Filing Rumah Sakit Kabupaten Semarang ini belum memiliki standar pengelolaan dokumen rekam medis aktif. Filing baru memiliki standar penyimpanan, pemusnahan, peminjaman, dan pengambilan dokumen rekam medis. Hal ini merupakan dugaan penyebab petugas hanya melihat dua angka terakhir pada nomor rekam medis untuk mencari subrak, baik sebelum mengambil maupun sebelum menjajarkan kembali dokumen rekam medis di rak penyimpanannya setelah digunakan untuk suatu keperluan. Sedangkan urutan dan kelompok dokumen rekam medis dalam satu kotak dengan berpedoman pada angka yang lain dari enam angka nomor rekam medis sering kali tidak diperhatikan, sehingga terjadi missfile.

\section{METODE PENELITIAN}

Penelitian ini adalah penelitian mix methode. Cara pengambilan data dilakukan dengan observasi dan wawancara. Pendekataan yang diambil adalah cross sectional.

Informan kunci dengan mewawancarai tiga orang petugas dan informan triangulasi adalah pimpinan subunit tertentu. ${ }^{(5)}$ Instrumen penelitian yang digunakan berupa pedoman observasi dan wawancara.

Pengolahan data dengan tahap perbaikan, pengelompokan, dan penyajian data. Selanjutnya, penyajian data akan dibandingkan dan dianalisis dengan berbagai teori untuk disimpulkan. Simpulan dimaksudkan untuk memudahkan dalam memberikan solusi dan saran. ${ }^{(6)}$

\section{HASIL PENGAMATAN}

Berdasarkan hasil penelitian, didapatkan bahwa:

1. Rumah Sakit Kabupaten Semarang ini memiliki 20 poliklinik yang terbagi atas dua lantai. Kedua lantai tersebut meliputi lantai 1 ada 14 poliklinik, yakni poliklinik mata, bedah mulut, penyakit dalam, jantung, syaraf, telinga hidung tenggorokan (THT), anak, jiwa, umum, dan fisioterapi. Sedangkan di lantai 5 terdapat 6 poliklinik 
(poliklinik bedah umum, digestif, gigi, onkologi, orthopedic, urologi, bedah plastik, dan bedah syaraf). Rumah sakit memiliki 3 ruang filing, yaitu pertama terdapat di lantai 1 (ruang filing rawat jalan sekaligus sebagai filing pusat), kedua di lantai 3 (kelanjutan dari ruang filing di lantai 1), dan ketiga terdapat di lantai 5 (ruang filing rawat inap).

2. Sarana pengelolaan dokumen rekam medis di filing meliputi: (a) sistem informasi yang digunakan untuk melayani peminjaman dokumen rekam medis pasien lama, (b) tracer yang merupakan outguide (alat pengganti dokumen rekam medis yang keluar dar rak file), (c) buku ekspedisi untuk mendokumentasikan serah terima dokumen rekam medis, (d) rak penyimpanan untuk menyimpan dokumen rekam medis. Berdasarkan hasil observasi, tracer ada, tetapi tidak digunakan secara optimal. Rak penyimpanan sudah menggunakan roll o'pack dan rak kayu, tetapi pembagian 100 kotak untuk subrak penjajaran terminal didit filing (TDF) belum dijalankan secara tertib.

3. Standar pengelolaan dokumen rekam medis yang tersedia ada dua jenis, yakni standar input/struktur dan standar operasional prosedur (SOP). Isi standar input pengelolaan dokumen rekam medis tersebut adalah (a) petugas berpendidikan DIII Rekam Medis dan Informasi Kesehatan (RMIK) dan berpenampilan menarik, (b) ketersediaan tracer, buku ekspedisi, serta komputer, (c) SOP tentang penyimpanan dan dan penjajaran dokumen rekam medis.

SOP pengelolaan dokumen rekam medis tersebut berisi tahapan : (1) penyimpanan dokumen rekam medis, meliputi; (a) petugas menerima dokumen rekam medis yang sudah lengkap di bagian rekam medis, (b) petugas memisahkan dokumen rekam medis menurut dua digit nomor akhir, (c) petugas menyusun sesuai dengan sistem terminal digit filing, (d) petugas menyimpan dokumen rekam medis dalam rak file menurut prosedur terminal digit filing.

(2) Pencarian kembali dokumen rekam medis, terdiri atas; (a) petugas menulis nomor rekam medis pada tracer, (b) petugas mencari dalam rak yang bertanda angka akhir dari nomor rekam medis pasien, (c) petugas mencatat data dokumen rekam medis yang dipinjam dalam buku ekspedisi, (d) apabila belum diketahui nomor rekam medisnya, maka petugas mencari melalui kartu indeks utama pasien (KIUP), kemudian mencarinya dalam rak penyimpanan dengan cara di atas, (e) apabila diketahui nomor rekam medisnya, maka petugas mencari di rak penyimpanan.

4. Sistem penomoran rekam medis di Rumah Sakit Kabupaten Semarang tersebut adalah unit numbering system karena seorang pasien hanya diberi satu nomor pada saat pertama kali datang berobat untuk berobat di semua unit. Pasien juga 
mendapatkan kartu identitas berobat (KIB) yang berisi nomor rekam medis pasien sebagai sarana melacak nomor rekam medis pasien tersebut jika datang berobat lagi ke rumah sakit.

5. Sistem penjajaran di filing menerapkan terminal digit filing (TDF). Definisi TDF menurut hasil wawancara dengan para petugas adalah :

penomoran rekam medis model ini dibagi ke dalam tiga kelompok. Contohnya sebagai berikut:

$$
\text { III II I }
$$

Digit angka I disebut primer yang menjadi petunjuk kotak di rak file, (b) kelompok II disebut kelompok sekunder sebagai penanda kelompok dokumen di rak file, (c) kelompok III merupakan kelompok tersier guna penentu urutan di rak penyimpanan. Berdasarkan hasil observasi, kode warna belum diterapkan untuk sistem penjajaran TDF ini.

6. Penyimpanan dokumen rekam medis yang digunakan adalah sistem desentralisasi. Terdapat dua jenis filing yang terpisah, yaitu filing rawat jalan dan rawat inap. Sistem penyimpanan dokumen rekam medis yang digunakan adalah berdasarkan nomor rekam medis terakhir pasien berkunjung. Nomor ini didapatkan jika pasien memiliki lebih dari satu nomor rekam medis. Hal ini terjadi apabila ada kejadian missfile, maka pasien akan dibuatkan folder baru dengan nomor baru juga.

Seorang pasien memiliki dua folder dokumen rekam medis, bila pasien dirawat inap, maka dokumen rekam medis pasien dikelola di penyimpanan rawat inap. Jika pasien dirawat jalan, maka dokumen rekam medis akan dikelola di penyimpanan rawat jalan. Pasien yang belum pernah berobat di rawat jalan, tetapi sudah pernah dirawat inap dan pasien tersebut datang untuk kontrol, maka petugas wajib membuat dokumen pasien tersebut dengan nomor rekam medis yang sesuai dengan nomor pada dokumen rekam medis rawat inapnya.

\section{PEMBAHASAN}

1. Tim Rumah Sakit dr. Cipto Mangunkusumo menyatakan bahwa penyimpanan dokumen rekam medis yang paling ideal adalah sentralisasi. Penyimpanan dokumen rekam medis seorang pasien seharusnya tergabung dalam satu folder terpusat di satu filing, baik dokumen rekam medis rawat jalan, rawat inap, ataupn gawat darurat, sehingga tercipta kesinambungan informasi medis seorang pasien.

Dengan demikian, teknik yang diterapkan oleh Rumah Sakit dr. Cipto Mangunkusumo tersebut dapat diaplikasikan di Rumah Sakit Swasta Kabupaten Semarang untuk kembali menerapkan sistem penyimpanan sentralisasi, meskipun poliklinik yang ada tersebar di lantai/gedung yang berbeda 
dengan keterbatasan kuantitas sumber daya manusia. Rumah sakit bisa membuka pos-pos terminal filing di setiap lantai/gedung yang terdapat polikliniknya untuk mendistribusikan dokumen ke berbagai klinik dan menyimpan dokumen selesai pelayanan sementara waktu di lantai/gedung yang sama. Apalagi jika seorang pasien berobat di beberapa klinik/unit pelayanan sekaligus. Hal ini akan mampu mengatasi keterbatasan sumber daya manusia dengan tetap memberikan pelayanan rekam medis yang cepat dan tepat bagi pasien. Contohnya, jika pasien penyakit dalam (Diabetes Mellitus) konsultasi tentang hasil pemeriksaan penunjangnya di klinik yang berada di lantai 1. Kemudian selanjutnya pasien tersebut diperkenankan untuk mendapatkan Tindakan cabut gigi di klinik gigi yang berada di lantai 5, maka perawat bisa membantu untuk menyerahkan dokumen rekam medis pasien ke terminal filing di lantai 5 agar petugas kurir tidak naik turun untuk mengantarkan dokumen rekam tersebut. Setelah pelayanan selesai, maka kurir filing akan mengambil dokumen rekam medis dari berbagai terminal. Hal ini harus disertai dengan dokumentasi srah terima yang tertib berupa buku ekspedisi di setiap terminal. (7)

Perubahan sistem penyimpanan desentralisasi ke sentralisasi juga bisa dilakukan secara bertahap, sehingga bisa berjalan dengan efektif dan efisien. Yakni, dengan menyediakan filing utama dengan rak yang sudah terbagi atas 100 subrak untuk penjajaran dokumen rekam medis secara TDF. Jadi, setiap selesai pelayanan, maka dokumen rekam medis rawat jalan, gawat darurat, serta rawat inap pasien baru/lama yang sudah tergabung menjadi satu folder disimpan di filing utama, tidak kembali ke filing lama. Dengan demikian, secara bertahap semua dokumen rekam medis pasien akan tersimpan secara sentraliasi.

2. Sarana ruang filing adalah segala sesuatu yang dipakai sebagai alat untuk mencapai makana dan tujuan. ${ }^{(8)}$ Sedangkan ketersediaan tracer belum digunakan secara tertib untuk mengendalikan kejadian missfile. Padahal tracer merupakan outguide (pengganti dokumen rekam medis yang dipinjam keluar. Dengan menerapkan tracer yang dilengkapi oleh kartu peminjaman dokumen, maka akan lebih mudah dan cepat dalam melacak keberadaan dokumen rekam medis yang belum kembali menurut ketentuan waktu yang telah ditetapkan. Selain itu, juga memudahkan dalam penjajaran kembali dokumen rekam medis yang selesai dipinjam karena ada outguide berupa tracer.

Rak-rak file yang tersedia, khsususnya yang berupa roll o' pack, harus terbagi secara jelas dalam 100 
kotak jika sistem penjajajaran yang diterapkan adalah TDF. Kemudian kotakkotak tersebut diberi penanda dua digit angka akhir dari enam digit nomor rekam medis yang ada, yakni mulai nomor 00-99. Dua digit angka akhir ini yang nanti akan diberi kode warna supaya dokumen rekam medis tepat berada dalam satu kotak dengan kode warna yang seragam.

3. Rumah Sakit Kabupaten Semarang ini sudah terakreditsi tahun 2017 dengan Standar Nasional Akreditasi Rumah Sakit (SNARS) 2017. Jadi, rumah sakit sudah mempunyai standar sebagai regulasi setiap subunit rekam medis yang lengkap. Subunit filing sudah mempunyai standar struktur/input dan SOP.

Hanya untuk standar input/struktur belum menyebutkan secara lengkap tentang sumber daya yang harus tersedia untuk mengelola dokumen rekam medis aktif, khususnya untuk mencegah kejadian missfile. Misalnya, untuk sarana bekum menyebutkan rak penyimpanan dengan 100 kotak, kode warna dan kartu peminjaman dokumen rekam medis yang harus menyertai tracer. Selain itu, harus menjelaskan kriteria dari setiap sumber daya. Contoh bahwa data minimal yang harus terangkum dalam kartu peminjaman dokumen rekam medis adalah nama peminjam, unit peminjam, waktu peminjaman, identitas petugas yang menyerahkan, waktu pengembalian dokumen rekam medis, dan paraf peminjam. Dengan adanya kriteria seperti ini, maka akan lebih operasional bagi setiap petugas filing untuk menyiapkan berbagai sumber daya berdasarkan standar input yang telah ditetapkan.

SOP yang merupakan suatu gambaran umum untuk karyawan mengenai cara kerja (langkah, urutan kerja) yang harus dilakukan, yang dipakai sebagai pegangan bila terjadi perubahan staf dan dapat digunakan untuk menilai efektivitas suatu sistem juga harus dibuat dalam tahapan yang rinci, sistematis, serta kalimat operasional. $^{(9)}$ Prosedur penjajaran dokumen rekam medis secara TDF seharusnya juga dijelaskan secara rinci dan sistematis tentang tahapan melaksanakannya. Mulai dari menjadikan dua digit angka akhir sebagai dasar melacak lokasi kotak rak dokumen, dua digit kedua (tengah) untuk kelompok dokumen dalam subrak, serta dua digit ketiga (depan) yang menunjukkan urutan dokumen dalam kotak rak tersebut.

Kejadian missfile diantaranya disebabkan karena penjajaran dokumen rekam medis hanya berpatokan pada angka akhir untuk melacak kotak dokumen. Sedangkan urutan dan kelompok dokumen tidak diperhatikan. Jika SOP direvisi dan disosialisasikan kepada semua petugas filing, maka langkah-langkah penjajaran dokumen rekam medis secara TDF akan dilaksanakan secara seragam oleh semua 
petugas. Hal ini akan menekan kejadian missfile.

Demikian juga tatacara pelacakan nomor rekam medis pada KIUP, seharusnya tahapannya dijelaskan secara rinci, sistematis, serta operasional dalam SOP. Mulai dari menanyakan nama pasien, mengindeks nama pasien, mencari KIUP sesuai dengan indeks nama pasien, serta menemukan nomor rekam medis pada KIUP.

SOP yang rinci, sistematis, serta operasional akan bisa digunakan sebagai daftar tilik. Daftar tilik ini digunakan untuk instrumen penilaian kepatuhan petugas dalam menjalankan tahapan kinerja sesuai dengan ketetapan SOP.

Perlu ditambahkan perumusan dan penetapan standar output/standar pelayanan minimal untuk indikator pencapaian mutu standar yang sudah ada. Misalnya, kejadian missfile di filing aktif $0 \%$, waktu maksimal pelacakan dokumen rekam medis 5 menit per dokumen 100\%, distribusi dokumen rekam medis dari filing ke poliklinik maksimal 10 menit per dokumen 100\%. Standar pelayanan minimal adalah ketentuan mengenai jenis dan mutu pelayanan dasar minimal bidang kesehatan yang merupakan urusan pihak manajemen/pemerintah dan berfungsi untuk panduan petugas dalam melakukan pelayanan. ${ }^{(11)}$

4. Sistem penomoran unit numbering system merupakan sistem yang ideal diterapkan bagi seorang pasien. Sebenarnya tujuannya adalah kesinambungan informasi medis karena jika pasien hanya mempunyai satu nomor rekam medis, maka diharapkan folder rekam medisnya bisa terlacak untuk dasar pengobatan berikutnya. Jadi, seharusnya sesuai dengan sistem penyimpanan dokumen rekam medis secara sentralisasi, tetapi rumah sakit malah kembali menerapkan sistem desentralisasi. Sarana pelacakan nomor rekam medis juga diterapkan oleh pihak rumah sakit dengan memberikan KIB kepada pasien agar dibawa setiap kali datang berobat.

Nomor rekam medis yang akurat sebagai identitas pasien merupakan pedoman pelaksanaan penyimpanan dan penjajaran dokumen rekam medis. Selain itu, juga sebagai petunjuk pencarian dokumen rekam medis di filing. ${ }^{(12)}$ Jadi, seharusnya sistem penomoran ini bisa mencegah kejadian missfile.

5. Sistem penjajaran dokumen rekam medis yang diterapkan di filing sudah ideal untuk mencapai prinsip retrivable, yakni TDF. Hanya saja, pelaksanaannya belum sepenuhnya menerapkan semua digit angka untuk menunjukkan lokasi dokumen rekam medis dengan valid. Pedoman penjajaran dan pelacakan dokumen rekam medis umumnya hanya berpatokan pada dua digit angka akhir untuk menunjukkan kotak dokumen dalam suatu rak. 
Penerapan TDF juga bisa membagi beban tanggung jawab petugas filing pada keamanan fisik dan isi dokumen rekam medis. (13) Contoh, petugas A diberi tanggung jawab terhadap rak file nomor 00-33, petugas $B$ diberi tanggung jawab terhadap rak file nomor 44-66 dan petugas C diberi tanggung jawab terhadap rak file nomor 55-99. Selain itu, petugas diberi tanggung jawab terhadap kecepatan dan ketepatan distribusi ke unit pelayanan dan pencegahan kejadian missfile.

Untuk itu, perlu juga diterapkan kode warna pada dua digit angka akhir. Kode warna juga salah satu sarana pengendali kejadian missfile.

Tabel 1. Kode Warna DRM

\begin{tabular}{|c|c|}
\hline Angka & Warna \\
\hline 1 & Purple \\
\hline 2 & Yellow \\
\hline 3 & Dark Green \\
\hline 4 & Orange \\
\hline 5 & Light Blue \\
\hline 6 & Brown \\
\hline 7 & Redness \\
\hline 8 & Light Green \\
\hline 9 & Redness \\
\hline 10 & Dark Blue \\
\hline
\end{tabular}

Sumber dari Departemen Kesehatan

Republik Indonesia ${ }^{(14)}$

6. Sistem desentralisasi yang memisahkan penyimpanan antara dokumen rekam medis pasien ke dalam dua folder menyebabkan informasi medis pasien tidak dapat berkesinambungan. ${ }^{(15)}$ Alasan supaya standar waktu pelayanan dokumen rekam medis pasien bisa tercapai sebenarnya bisa diatasi dengan mengelola sumber daya dengan optimal.

Apalagi jika dokumen rekam medis missfile, seharusnya pasien dibuatkan folder baru dengan nomor rekam medis yang sesuai dengan KIB. Jika dokumen bisa ditemukan lagi, maka tinggal menggabungkannya dengan dokumen rekam medis yanga baru. Dengan demikian, kesinambungan informasi medis pasien tetap tercapai. ${ }^{(16)}$

\section{KESIMPULAN}

1. Sistem penyimpanan desentralisasi diterapkan karena berbagai polikinik berada secara terpisah lantai/gedung, sehingga dimaksudkan untuk mempercepat pelayanan dokumen rekam medis.

2. Sarana yang ada belum digunakan secara optimal, khususnya dalam pengendalian kejadian missfile. Selain itu, ada beberapa sarana pengendalian kejadian misfile yang belum ada, seperti kode warna.

3. Standar input yang ada belum menjelaskan kriteria sumber daya secara lengkap. SOP belum menjelaskan tahapan kinerja kegiatan secara rinci, sistematis, dan operasional. Selanjutnya, belum ada indikator mutu berupa SPM. 
4. Sistem penomoran unit numbering system dengan sarana KIB yang diberikan kepada pasien sudah ideal untuk mengidentifikasi dokumen rekam medis secara mudah, cepat, serta tepat.

5. Sistem penjajaran terminal digit filing juga merupakan sistem penjajaran yang ideal untuk mengidentifikasi dokumen rekam medis pasien secara mudah, cepat, serta tepat.

6. Sistem penyimpanan desentralisasi menyebabkan ketidaksinambungan informasi medis pasien, serta menjadi salah satu faktor penyebab kejadian missfile.

\section{SARAN}

1. Jangka pendek dengan pembukaan pospos terminal filing di setiap lantai/gedung supaya memudahkan dan mempercepat pelayanan rekam medis.

2. Kedisiplinan dalam pengadaan dan pemanfaatan sarana pengendalian missfile diatur dalam kebijakan dan standar rumah sakit.

3. Revisi standar input dengan melengkapi sumber daya yang dibutuhkan dalam suatu kegiatan dan memperjelas kriteria masing-masing sumber daya. Revisi SOP supaya tahapan setiap kegiatan lebih rinci, sistematis, serta operasional, sehingga memudahkan petugas dalam melaksanakannya.

4. Komitmen untuk mengembalikan sistem penyimpanan desentralisasi ke sentralisasi secara bertahap untuk menjamin kesinambungan informasi medis pasien guna keselamatan pengobatan pasien berikutnya.

\section{SAMBUTAN}

Tim penulis menyampaikan terimakasih kepada pimpinan dan staf lahan penelitian di Rumah Sakit Kabupaten Semarang. Selain itu, kami juga mengucapkan terimakasih kepada Civitas Akademika Universitas Dian Nuswantoro Semarang yang telah turut mendukung penelitian ini berjalan dengan sukses.

\section{KETERSEDIAAN DATA}

Data yang relevan telah tersedia. Penelitian ini bermaksud memberikan solusi terhadap kejadian missfile dan ketdaksinambungan informasi medis pasien.di filing rumah sakit. Dengan demikian, diharapkan dokumen rekam medis pasien yang datang berobat Kembali bisa terlacak secara retrivable (sewaktu-waktu dibutuhkan dokumen rekam medis mudah dan cepat teridentifikas). Selain itu, dengan penerapan kembali sistem penyimpanan dokumen rekam medis secara sentralisasi, maka informasi medis seorang pasien akan berkesinambungan untuk menjamin keselamatan pengobatan pada diei seorang pasien.

\section{PENYANGKALAN}

Hasil penelitian ini tidak mengandung konflik kepentingan antara penulis dengan lahan penelitian. Hasil penelitian digunakan untuk kepentingan pengembangan ilmu 
pengetahuan, khususnya bidang ilmu Rekam Medis dan Informasi Ksesehatan. Dana penelitian berasal dari dana mandiri tim penulis. Selanjutnya, hasil penelitian dipublikasikan supaya bermanfaat bagi lahan penelitia dan rumah sakit yang sejenis.

\section{PERTENTANGAN KEPENTINGAN}

Penulis menyatakan bahwa penelitian ini tidak mengandung pertentangan kepentingan.

\section{DAFTAR PUSTAKA}

1. Peraturan Menteri Kesehatan Republik Indonesia Nomor 56 Tahun 2014 tentang Klasifikasi dan Perizinan Rumah Sakit. Permenkes RI. 2014;1(4):53.

2. Peraturan Menteri Kesehatan Republik Indonesia Nomor 269/Menkes/PER/III/2008 entang Rekam Medis.

3. Departemen Kesehatan Republik Indonesia. Buku Sistem Pencatatan Medik Rumah Sakit. 1982.

4. Retno Astuti Setijaningsih. Pemanfaatan Kode Warna untuk Memudahkan Pelacakan Berkas Rekam Medis. Visikes Jurnal Kesehatan. 2004;3:41-7. Fakultas Kesehatan Universitas Dian Nuswantoro.

5. Lexy. J. Moleong. Metodologi Penelitian Kualitatif. Rosdakarya : Bandung. 2004.

6. Notoatmodjo S. Metodologi Penelitian Kesehatan. Jakarta: Rineka Cipta. 2005.

7. Basir B. Manajemen Kearsipan, Bumi Aksara. Jakarta. 2000.
8. Putri A. Analisis Tata Ruang Tempat Penyimpanan. 1st edision. 2014;3:41-9.

9. Departemen Kesehatan Republik Indonesia. Petunjuk Teknis Penyelenggaraan Rekam Medis/ Medical Record Rumah Sakit. Jakarta. 1991.

10. Hatta GR. Pedoman Manajemen Informasi Kesehatan di Sarana Pelayanan Keseahatan. Jakarta: UI Press; 2013.

11. Ishak Hasanuddin. PMK No 4 Th 2019 tentang Standar Teknis Pelayanan Dasar pada Standar Pelayanan Minimal Bidang Kesehatan. Society. 2019.

12. Wintri S. Sistem Penyimpanan, Penomoran dan Penjajaran Rekam Medis. 2011

13. Miller K. Being a Medical Record Clerk. Prentice Hall. 2000.

14. Departemen Kesehatan Republik Indonesia. Pedoman Rekam Medis Rumah Sakit di Indonesia Revisi I. Dirjen Pelayanan Medis, Jakarta. 1991.

15. Departemen Kesehatan Republik Indonesia, Pedoman Pengelolaan Rekam Medis Rumah Sakit di Indonesia, Jakarta, 1997.

16. R. P. Patel MPP and AMS. Undang Undang Republik Indonesia Nomor 43 Tahun 2009 tentang Kearsipan. 